\title{
EVOLUCIÓN Y CRISIS DE UNA POBLACIÓN CAMPESINA
}

\author{
POR \\ JORGE OSVALDO MORINA
}

\section{CONSIDERACIONES INTRODUCTORIAS}

En este trabajo, abordamos la evolución del campesinado de Iruya, provincia de Salta, en un extenso período que va desde comienzos del siglo XIX hasta los primeros años de la década de 1990. Hasta aproximadamente 1960, presentamos una reseña de las etapas atravesadas por la zona y su población, dentro de un marco histórico-regional. Desde entonces hasta la actualidad se acelera un proceso que es analizado como de crisis y descomposición de la economía campesina.

Cabe decir aquí, que existen posiciones controvertidas sobre la suerte que correrá el campesinado en América Latina. Por un lado, la visión descampesinista, por el otro, la campesinista.

La interpretación campesinista sostiene la posibilidad de persistencia y hasta recomposición de la forma de produción campesina bajo el capitalismo. El enfoque descampesinista sugiere la existencia de una tendencia a la disolución y desaparición del campesinado, a través de su inevitable proletarización en el marco de la intensificación de las relaciones capitalistas en el campo (Heynig, 1982).

En este estudio, se entiende a la economía campesina como una forma de organización social de la producción específica (Schejtman,

Jorge Osvaldo Morina: Centro de Investigaciones Geográficas, Facultad de Ciencias Humanas-UNCentro. Pinto 399 (7000) - Tandil (Bs. Aires)

Estudios Geográficos

Tomo LIX, n. ${ }^{\circ} 233$, octubre-diciembre 
1980). Las respuestas a qué, cómo y cuánto producir, quién produce y qué destino se le dará a la producción, definen una lógica y encaran la consecución de un determinado objetivo, central para la unidad productiva.

En cuanto a la unidad de producción campesina, funciona como una familia que pone en marcha su trabajo para producir lo que necesita. Los caracteres que deben ser destacados pueden sintetizarse en:

1. Carácter familiar de la unidad de producción.

2. El objetivo de la unidad campesina es la reproducción de los productores y de la propia unidad.

3. La disponibilidad de recursos (tierra, tecnología) es escasa.

4. La producción campesina tiene carácter parcialmente mercantil.

5. La producción campesina es una forma de producción subordinada, económica, social y políticamente.

En cuanto al área seleccionada (Iruya), señalamos que es uno de los 23 departamentos en que se encuentra dividida la provincia de Salta, ocupando parte del norte de ella, con una extensión de $3515 \mathrm{Km} 2$ (ver Fig. 1). El Censo Nacional de 1991 registró 5.824 habitantes, entre agrupados y dispersos, todos considerados rurales. Administrativamente, limita por el norte con Santa Victoria (Salta), por el este y el sur con Orán (Salta) y por el oeste con Humahuaca (Jujuy).

\section{Marco HistóRICo-Regional (1810-1960 APROXIMADAmEnTe)}

Para lograr una exposición más clara de la evolución socio-económica del área y su población, se procedió a una periodización que emana de los cambios en la división territorial del trabajo tanto a nivel nacional como regional y de las expresiones locales consecuentes.

Aclaramos aquí, que el análisis explicativo-interpretativo que compone este apartado, toma conjuntamente los departamentos de Santa Victoria e Iruya, por constituir el subespacio de los valles altos, ocupado por una población de problemática socio-territorial y ambiental similar. 


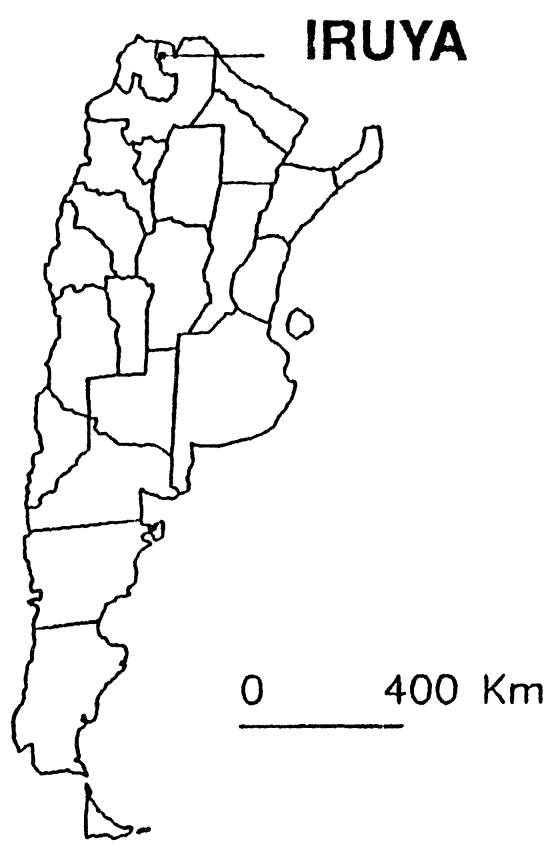

Fig. 1.-Ubicación del Departamento Iruya.

Período Poscolonial (1810-1920 aproximadamente)

El subespacio en cuestión (Santa Victoria e Iruya) formó parte de un extenso fundo, el marquesado de Tojo, de alrededor de 2.000 .000 de hectáreas, creado en 1707. El marquesado tenía centro en Yavi, caserío del actual departamento homónimo en la provincia de Jujuy, pero incluía vastas áreas del altiplano argentino-boliviano. La aptitud agrícola de los valles altos permitía producir forraje para el tráfico de mulas que pasaba por Yavi (Reboratti, 1974).

Hasta 1810, la producción de haciendas y encomiendas del Noroeste argentino, incluyendo la zona específica que nos ocupa, se orientó en particular hacia la venta en los mercados constituidos por los centros mineros altiplánicos. La asignación de parcelas a los campesinos tenía como finalidad esencial, la reproducción de la fuerza de trabajo y su mantenimiento en el seno de la hacienda (Madrazo, 1982; Fidalgo, 1988). El arriendo era una figura poco difundida en el área. El plustrabajo del 
campesinado era apropiado por el hacendado o encomendero y transformado en dinero mediante la circulación mercantil.

La declinación potosina primero, y la revolución de mayo después, cuestionaron la articulación al espacio altoperuano, abriéndose desde 1810 una larga etapa de transición que afectó decisivamente al área. Después de 1850 los núcleos dinámicos del altiplano se basaban en la explotación argentífera. Los nuevos centros mineros estaban al sur de Potosí y cerca de la ruta que unía Potosí con Jujuy, a través de Tupiza. El dinero de plata que durante el siglo XIX circulaba en Salta y Jujuy provenía de Bolivia, y se obtenía mediante la exportación de mercancías al altiplano. Buena parte de ese dinero iba a la costa del Pacífico para comprar bienes de consumo europeos o norteamericanos.

Con el cierre de la frontera y la abolición de la encomienda y la mita, gana importancia la relación social conocida como propiedad de la tierra. Aparecen las listas de arrenderos (arrendatarios) de las grandes propiedades y la renta de la tierra reemplaza al comercio. No sólo se comenzó a cobrar arriendo a los antiguos encomendados, sino también a otros pobladores que nunca habían dependido del marquesado (Fidalgo, 1988). Los propietarios de las haciendas buscaron en la percepción de una renta en dinero o en bienes, obtener ingresos que dejaban de llegar por la colocación de productos en el mercado altoperuano en declinación (Madrazo, 1982; Rutledge, 1987).

La población local, integrada por indígenas-campesinos, mantuvo la base económica del período prehispánico: actividades de subsistencia basadas en la agricultura y en la ganadería extensiva, aún cuando durante el período colonial se introdujeron nuevos cultivos (trigo y forrajeras) y se cambió parcialmente el tipo de animales de cría, al incorporar ovejas, cabras y vacunos en lugar de llamas y vicuñas.

La produción de distintos pisos ecológicos era trocada en base a tasas de intercambio fijadas con anterioridad, generalmente estables. El vínculo entre grupos aparentemente aislados se concretaba en el marco de una extensa red de núcleos productivos con acceso al control vertical de tierras altas y bajas (Golte, 1980; Madrazo, 1981). De todos modos, la autonomía relativa de cada comunidad y del conjunto de ellas, se veía seriamente restringida por la relación asimétrica establecida entre campesinos y terratenientes. En general, las transacciones comerciales ocurridas en las rutas al Alto Perú tuvieron como beneficiarios a los hacendados y mercaderes. 
Los originarios debían abonar rentas que afectaban severamente la economía doméstica; a esto se sumaban las obligaciones con el gobierno provincial. Una larga serie de documentos y peticiones de indígenas de la puna, quebrada de Humahuaca y valles de altura (como Valle Grande, en Jujuy, Santa Victoria e Iruya, en Salta) se dirigen a las autoridades provinciales en reclamo contra los terratenientes. Hasta fines del siglo XIX continuaron los reclamos, entre los cuales puede destacarse un documento de 1882 presentado ante el gobierno por campesinos de Santa Victoria e Iruya. En el escrito, se quejan de la conducta de los «detentadores de la tierra» que aumentan el costo de los arriendos (pagos por los predios agrícolas, derechos de pastaje) y cometen otros abusos, como contar en más el ganado para cobrar mayores derechos (Imprenta del Pueblo, 1882).

La intensificación de los conflictos y la sangrienta represión del levantamiento campesino cuestionaron la viabilidad a largo plazo del sistema de hacienda. El centro del conflicto era el control sobre la tierra.

$\mathrm{El}$ «aislamiento» de los valles altos se completó hacia 1907/8 con la habilitación del ferrocarril Jujuy-La Quiaca, y la conexión con el ramal boliviano.

Mientras, en las últimas décadas del siglo, comenzó el crecimiento del área de los valles bajos (valle del río San Francisco), orientada al mercado interno nacional. La expansión de la actividad azucarera en Jujuy y Salta complementó un proceso de integración regional al sistema nacional, iniciado en Tucumán con la misma agroindustria.

\section{Integración Subordinada (1920-1960 aproximadamente).}

Expansión de la agroindustria azucarera.-La producción del valle del San Francisco tenía restringida su comercialización a Salta y Jujuy, y en parte a Bolivia. En esa época se produce el acaparamiento de tierras en los valles bajos y algunos ingenios comienzan su modernización técnica. A principios de la década de 1880 la integración política del noroeste argentino permite a las oligarquías provinciales participar ampliamente en el gobierno nacional y en la definición de políticas favorables al sector azucarero (Rutledge, 1987).

El ferrocarril ingresó en el valle del San Francisco hacia 1907 (en al- 
gunos tramos), llegando a Embarcación en 1912. Conectaba así la producción azucarera de Salta y Jujuy con el mercado nacional. En las primeras décadas de este siglo la producción salto-jujeña se incrementa y adquiere envergadura.

En 1920 la contribución de Salta y Jujuy, en conjunto, alcanzaba el $15,7 \%$ de la producción nacional de azúcar. Tucumán aportaba el 82,3\%. En 1930, la participación de Salta y Jujuy ascendió al 25,3\%, mientras la de Tucumán bajó al 72,1\%.

Esta agroindustria requiere volúmenes variables de mano de obra a lo largo del año. La necesidad de trabajadores se multiplica notoriamente durante los meses de zafra, mayo/junio a octubre/noviembre, según las zonas.

Hacia fines del siglo pasado y en las primeras décadas del actual, la mano de obra de los ingenios estaba constituida mayoritariamente por indígenas chaqueños. Se reclutaba en general, aborígenes chiriguanos, tobas, matacos, chorotes, mocovíes y pilagás, actuando el ejército como factor de coerción y control.

Hacia 1930, la integración de las tierras bajas al mercado nacional era casi completa. La economía agraria del valle del San Francisco había experimentado grandes cambios en su estructura. Simultáneamente, los departamentos de Santa Victoria e Iruya (como así también áreas similares y la puna jujeña) y su población campesina, comenzarían a cumplir una nueva función en la modificada división regional del trabajo.

Distorsión de la economía de autosubsistencia.-Sobre el final de los años 20 y durante los años 30 se produjo el reemplazo masivo de la mano de obra estacional chaqueña por campesinos de la puna y valles de altura. La expansión de los cultivos de algodón incrementaron los requerimientos estacionales de trabajadores en la planicie chaqueña. Los indígenas chaqueños también eran utilizados en los cañaverales de su propia región.

Cabe consignar que, los últimos meses de la cosecha de algodón coinciden con los primeros de la zafra azucarera en Jujuy y Salta. En 1924 el gobierno del Territorio del Chaco prohibió la salida de sus indígenas; el gobierno nacional se expidió ese mismo año en igual sentido, reiterando el decreto en 1927.

Desde 1923 en adelante, varias haciendas de la puna y valles de altura fueron compradas o alquiladas por ingenios azucareros. En esta con- 
centración de tierras se destacó San Martín del Tabacal, que entre 1923 y 1940 aproximadamente, llegó a controlar algo más de 930.000 has. Varios departamentos de Salta y Jujuy quedaron bajo el control de la familia Patrón Costas, propietaria del citado ingenio. Entre ellos, los de Iruya y Santa Victoria (Rutledge, 1987).

En Santa Victoria, Robustiano Patrón Costas pactó con su propietaria, Hortensia Campero de Figueroa, el arriendo de la Hacienda Santa Victoria, de más de 223.000 has.; en Iruya, adquirió en propiedad la Hacienda Santiago, de casi 172.000 has., actuando como comprador («fachada» o «cubierta» del ingenio) la Compañía Territorial del Norte S.A. (República Argentina. Congreso Nacional, 1949).

La política de acumulación de tierras tuvo como objetivo esencial, la mano de obra estacional (hasta entonces potencial desde la mira de los ingenios) que habitaba las mismas y que podía ser utilizada en los trabajos de la zafra azucarera.

Se estableció así la relación entre plantaciones y haciendas, surgiendo aspectos típicos de la conexión entre el sector capitalista y el sector llamado de subsistencia. La economía capitalista ejerce control sobre el conjunto de tierras de economía campesina periférica, y a través del control territorial, sobre la productividad de su trabajo. Los campesinos de Iruya y Santa Victoria debieron concurrir a la zafra azucarera (especialmente a San Martín del Tabacal) para mantener su parcela.

Desde entonces, el pago del arriendo se vinculó estrechamente al trabajo extrapredial en las plantaciones. Ante la negativa campesina a migrar, se hizo común el uso de la fuerza pública, en un verdadero sistema de reclutamiento compulsivo (Reboratti, 1974; Whiteford, 1977; Bianchetti, 1978). Se instauró un régimen obligatorio de trabajo en la zafra, mantenido hasta los primeros años de la década de 1940. Era la primera fase del proceso de proletarización de los campesinos.

Las diversas estrategias de las empresas azucareras articularon «el uso de la coacción con los incentivos monetarios, asumiendo esta combinación distintas formas en función de las particularidades de los grupos humanos captados, la resistencia de los trabajadores, la evolución de la oferta y la percepción de las élites sobre la mayor eficiencia y productividad de la mano de obra que se movilizaba sin coerciones extraeconómicas. [...] el peso del componente coactivo fue disminuyendo progresivamente y asumiendo mayor importancia relativa el incentivo salarial» (Campi, 1996: 47). 
La economía de «autosubsistencia» se vio notoriamente distorsionada a partir de la exportación estacional de fuerza de trabajo y la paulatina monetización, derivada del contacto de los campesinos con pautas y modalidades de consumo que fueron penetrando en la zona que analizamos.

La salida estacional de la fuerza de trabajo deteriora rápidamente el ciclo productivo de la agricultura local, al reducirse notablemente el tiempo que se invertía en un grupo de actividades de apoyo a la actividad agrícola propiamente dicha y en las diferentes actividades artesanales complementarias.

Articulación efectiva a la economía regional.-El gobierno militar establecido en junio de 1943 sancionó al año siguiente la Ley 12921, conocida como Estatuto del Peón. Este incluía una sección para la industria azucarera que tuvo repercusión en las plantaciones. Entre otros propósitos, se orientaba a elevar los salarios y mejorar las condiciones de trabajo. Posteriormente, los gobiernos justicialistas (1946-1955) trataron de continuar con las reformas laborales.

Junto al Estatuto del Peón, comenzó un período de agitación rural con respecto a la tenencia de la tierra. En el marco de la campaña electoral previa a los comicios nacionales de 1946, se publicaba la supuesta decisión de la fuerza política que luego asumió el gobierno, de expropiar varias haciendas controladas por la familia Patrón Costas. Para la misma época se suceden los pedidos de expropiación por parte del campesinado de la puna y valles altos. Aunque la cuestión de las tierras se debatió en el Congreso Nacional en 1949, con ninguna de las fincas de Iruya y Santa Victoria se llegó a la expropiación. Sin embargo, la posibilidad de ella llevó a San Martín del Tabacal a desprenderse del control directo de algunas haciendas, sin dejar de ejercer influencia sobre la población campesina.

Mientras tanto, el dinero o sus equivalentes, como mercaderías o vales de ingenios, habían penetrado decisivamente, haciendo muy desiguales las relaciones entre los campesinos y los comerciantes locales. Estos eran con frecuencia, funcionarios públicos y contratistas de mano de obra.

Los contratistas, encargados de asegurar a los ingenios el número de zafreros requerido cada año, fueron tomando cada vez mayor importancia. El paulatino reemplazo del reclutamiento forzado por el me- 
canismo de endeudamiento, indica la consolidación de una economía monetizada cualitativamente diferente a la existente antes de 1920.

La situación descrita determinó un estímulo a la proletarización y una integración mayor (y cada vez más subordinada) a la sociedad global. La combinación entre actividades de subsistencia y venta temporal de fuerza de trabajo pasó a ser parte de la estrategia reproductiva campesina, y no sólo de reproducción de los ingenios.

Finalizando la década del 50 y a comienzos de los años 60 , se advierte que la tierra apta para agricultura es muy escasa y la tenencia por parte de los campesinos, harto precaria. La demanda estacional de braceros moviliza a la población durante los meses dedicados a los trabajos de ampliación de cultivos. Entre mayo y setiembre/octubre, marchan a la zafra (sobre todo a San Martín del Tabacal), no sólo los hombres, sino también mujeres y niños de Santa Victoria e Iruya.

El campesinado no puede acceder a medios de producción suficientes como para reproducirse, generándose una superpoblación relativa a su interior. Es esta superpoblación la que encontrará salida a través de la demanda extralocal de trabajo en el complejo agroindustrial azucarero de los valles bajos.

\section{DeSESTRUCTURACiÓn DEL CAMPESINADO: 1960 HASTA LA ACTUALIDAD}

En este apartado, hacemos referencia en primer lugar a la sensible decadencia de las actividades productivas locales. Esto se vincula estrechamente al proceso de semiproletarización, que se constituye en el eje para estudiar la situación campesina. Este proceso presenta dos componentes fundamentales: la venta estacional de fuerza de trabajo propiamente dicha, y el avance crucial de la economía monetaria y mercantil, con pautas de la sociedad global.

El centro de la interpretación estará dado por las características que desde los años 60, vienen asumiendo los mecanismos de subordinación. Aunque las fuentes secundarias y el trabajo de campo constatan una realidad asimilable a Santa Victoria e Iruya, por razones de espacio nos dedicamos aquí, al último de los departamentos mencionados. 


\section{La declinación productiva de las últimas décadas}

Un aspecto a remarcar es el de la alta concentración de la tierra. El Censo Nacional Agropecuario (CNA) de 1969, registra para Iruya 273 explotaciones, ocupando 322.488 has. Las unidades menores (hasta 5 has.) explican el 73,3\% del total, pero ocupan sólo el 0,1\% de la superficie. Se trata de 200 explotaciones en 388 has. En el otro extremo, 9 explotaciones de más de 10.000 has.(3,3\% del total), ocupaban 220.043 has., es decir, el $68,2 \%$ de la superficie. Las tierras en propiedad se concentran en los estratos de mayor extensión. Merece aclararse, además, que en ese relevamiento fueron excluidas las parcelas de menos de 1 ha., dedicadas en general al autoconsumo.

Los datos presentados evidencian la dificultad para acceder a la tierra por parte de los campesinos. Más del $70 \%$ de las explotaciones eran consideradas subfamiliares.

En 1979, el Censo Agropecuario de la Provincia de Salta, mostraba que el $89 \%$ del total de explotaciones abarcaba sólo el 0,5\% de la superficie relevada (616 has. sobre 128.000 has.). Una sola explotación (aún existente) comprendía el $98 \%$ de la superficie total, esto es, 125.000 has. Se trata de la Finca Santiago, que con menos extensión, seguía siendo la mayor de Iruya. Reaparece en este relevamiento provincial la propiedad latifundista que, probablemente, una división en arriendos ocultaba parcialmente en registros como el de 1969.

Si deseamos aproximarnos al tipo de explotaciones podemos confrontar el CNA de 1969 con el CNA de 1988. En ambos registros se observa el absoluto predominio de la fuerza de trabajo familiar, que pasa de $94 \%$ a $97 \%$.

Teniendo en cuenta el personal permanente y el número de hectáreas cultivadas obtenemos la densidad ocupacional, de preocupante incremento en veinte años (Cuadro I).

CuAdRo I

DENSIDAD OCUPACIONAL

\begin{tabular}{l|c|c|c}
\hline Año & Personal & Sup. Agrícola (has.) & Densidad (trabaj./ha.) \\
\hline 1969 & 1.041 & 681 & 1,5 \\
1988 & 1.125 & 367 & 3,1 \\
\hline
\end{tabular}

Fuente: Censos Nacionales Agropecuarios de 1969 y 1988. 
Como veremos en las próximas páginas, no se observan incrementos de productividad que permitan suponer que menos tierra alcanza para más personas. La pauperización del campesinado resulta cada vez más aguda.

La tendencia al deterioro de la producción campesina, se puede inferir también desde la evolución de la superficie cultivada entre 1960 y 1988 (Cuadro II). Si incorporamos los datos de población, es fácil comprobar la rápida declinación de las últimas décadas en términos de superficie cultivada/habitante (Cuadro III).

\section{CuAdro II}

SUPERFICIE AGRÍCOLA EN LOS TRES ÚLTIMOS CNA

\begin{tabular}{l|c|c|c|c|c|c}
\hline & \multicolumn{3}{|c|}{ Años } & \multicolumn{3}{c}{ Variación intercensal (\%) } \\
\hline & $\mathbf{1 9 6 0}$ & $\mathbf{1 9 6 9}$ & $\mathbf{1 9 8 8}$ & $\mathbf{6 9 / 6 0}$ & $\mathbf{8 8 / 6 9}$ & $\mathbf{8 8 / 6 0}$ \\
\hline Has. & 1.095 & 681 & 367 & -38 & -46 & -66 \\
\hline
\end{tabular}

FUENTE: CNA. 1960, 1969 y 1988.

CUADRo III

SUPERFICIE AGRÍCOLA Y POBLACIÓN

\begin{tabular}{c|c|c|c}
\hline Año & Población & Sup. Cultivada & Sup. Cultiv./hab. \\
\hline 1960 & 3.489 & 1.095 & 0,31 \\
1969 & 4.344 (a) & 681 & 0,16 \\
1988 & 5.824 (b) & 367 & 0,06 \\
\hline
\end{tabular}

(a) Población según el Censo Nacional de 1970.

(b) Población según el Censo Nacional de 1991.

NotA: en 1960 y 1970 , el censo poblacional se realizó cuando los migrantes estacionales estaban fuera de Iruya. En 1991, la mayor parte de los campesinos semiproletarizados aún no se habían marchado, el 22 de mayo. En el 60 y en el 70, el relevamiento fue en setiembre, en plena zafra.

FuENTE: CNA 1960, 1969 y 1988. CNP 1960, 1970 y 1991.

Por otra parte, las explotaciones y la superficie dedicada a los cultivos más difundidos, hablan de una clara orientación al autoconsumo, pero con retracción significativa en productos que constituyen la base alimentaria de la familia campesina. Nos referimos, especialmen- 
te, al maíz y la papa, que han tenido entre 1960 y 1988, una sensible merma. Debemos señalar además, la casi desaparición de ciertos cultivos que otrora constituían elementos importantes en la dieta local. Es el caso de la quinoa y el trigo. Este último, ya en 1960 se había reducido a 33 has., sólo el 3\% de la superficie cultivada. En 1988, no aparece registrado en el CNA, y si bien nuestro trabajo de campo verifica la existencia de pequeñísimas parcelas con trigo, su peso relativo resulta insignificante.

En estricta relación con los ambientes, el calendario agrícola se extiende entre fines de invierno y mediados de otoño. En los sitios de mayor altura (por encima de los 3000 metros s.n.m.), la siembra se inicia hacia el mes de agosto, en las terrazas del fondo de los valles, donde el riego permite los primeros trabajos de arado. Previamente, durante el otoño y el invierno, se concretan las tareas de despiedre y el abono (generalmente guano de cabra). La siembra se hace con la propia semilla producida por el agricultor. Eventualmente, como suele ocurrir con la papa y el maíz, se compra en los pueblos o se obtiene a través de intercambios con otros campesinos. Las primeras siembras corresponden a los cultivos más resistentes (habas, arvejas y oca).

En los valles medios (entre 2000 y 2500 metros s.n.m. aproximadamente), alrededor de pueblos como Santa Victoria e Iruya, la siembra comienza en primavera, y con las primeras lluvias de octubre, se inicia en los faldeos. Predominan el maíz y la papa, y se advierten pocas y reducidas parcelas para el trigo. El último turno es el de la cebada y la alfalfa, para alimentar el ganado en invierno, correspondiendo a las primeras semanas de diciembre. La cosecha comienza con el verano en las zonas altas, y se extiende hasta abril, alternando cultivos y niveles altitudinales (Morina, 1992). Por otra parte, se observa la presencia de intercambios equilibrados al interior de los rodeos, entre campesinos de tradición agrícola vallista y otros de tradición pastoril. Así, es frecuente el cambio de maíz por carne de ovejas o de cabras. Varios entrevistados confirman que obtienen carne entregando alguno de los principales productos agrícolas, maíz o papas. La tasa de intercambio en estos casos, es de 40 kg. de maíz por un cabrito sin cuero, o de media bolsa de papas (unos 25 Kg.) por un cordero carneado, o $30 \mathrm{Kg}$. de maíz por un cordero carneado.

También son comunes otras transacciones, incluyendo, en ciertos casos, productos no campesinos: 2 bolsas de papa por 1 de azúcar; 2 panes de sal por 1/2 bolsa de papas o maíz; 1 bolsa de papas por 1 bolsa de ha- 
rina industrial; 1 bolsa de papas por una de maíz. El trueque utiliza medidas de uso común en el noroeste colonial, como «la carga» (unos 30 Kg.), la arroba (11 Kg.) y el almud (unos $6 \mathrm{Kg}$.).

Agreguemos que, el ganado más difundido es el ovino, luego el caprino y por último el bovino. Sólo en las tierras más altas, y en casos muy puntuales, pueden observarse apreciables rebaños de llamas. Los vacunos se manejan a lo largo del año en un sistema de trashumancia complejo, ya que cada ganadero aprovecha sus propios campos de veranada e invernada, en un contexto de recorridos generales de diseño similar.

La calidad y estado sanitario es, en general, muy deficiente. La actividad ganadera requiere menos dedicación que la agricultura, quedando a cargo de niños y ancianos durante varios meses al año. El tamaño del rebaño está relacionado con la disponibilidad de mano de obra familiar para cuidarlo, aunque eventualmente se combina la fuerza de trabajo de varias unidades campesinas. En Iruya, el $54 \%$ de las familias posee vacunos y el $67 \%$ ovinos. El tamaño promedio de los rebaños es de 100 ovinos y 12 vacunos (Oclade, 1988).

El cuero y la lana de los animales es entregada en los almacenes por dinero o por productos industrializados. Durante décadas, el principal destino de la lana era el hilado para los tejidos locales. La artesanía textil subsiste en algunos parajes, pero en general, la lana es cada vez más un producto para el intercambio.

Otra constatación in situ, es la pérdida de habilidades en prácticas básicas para la agricultura, como por ejemplo, el amansamiento de bueyes para el arado. Los jóvenes piensan en un futuro fuera de la zona: «muchos se han marchado, no quieren esta vida», afirmaba un entrevistado de edad avanzada, sintetizando en esas palabras el proceso de transformación cultural.

Un fenómeno relativamente difundido es el movimiento intradepartamental de familias que ocupan parcelas y viviendas en distintos pisos ecológicos. Estas migraciones se orientan a la subsistencia mediante el aprovechamiento del trabajo familiar durante todo el año.

En años recientes se han puesto en práctica diversos planes y programas, como los de huertas familiares y comunitarias; de mejoramiento de la sanidad animal; cooperativas de artesanos; etc. Se contó para ello, con el asesoramiento de la Dirección General Agropecuaria de Salta y del INTA de Abra Pampa, entre otros organismos. Sin embargo, estos planes carecen de continuidad, y aún cuando la tuvieran, su al- 
cance estaría restringido a determinadas comunidades y estratos campesinos.

Se nos ha recalcado la necesidad de extensión agropecuaria permanente y adaptada a las condiciones culturales y fisiogeográficas de Iruya, sugiriendo poner énfasis en acciones orientadas a la forestación (en especial para control de erosión), agricultura y ganadería. Un problema concreto es la falta de selección de semillas, que ocasiona menores y peores cosechas. Por otra parte, y en concordancia con algunos actores locales, como productores ya vinculados al mercado, maestros, ciertos comerciantes, los técnicos proponen mejorar y aumentar la producción de cultivos que hoy alcanzan mercados locales, e incorporar otros cultivos a los circuitos comerciales. Como ejemplo de esto último, podemos citar la quinoa, el comino y el amaranto. En materia ganadera se menciona la posibilidad de incrementar la cría de camélidos, que son poco deteriorantes del medio y podrían reportar ingresos.

Sin embargo, entre las dificultades que los propios informantes advierten para sus ideas, podemos destacar: la falta de recursos para obtener herramientas de labranza, semillas, fertilizantes, y sobre todo, la escasa predisposición para tomar el hábito de incorporar otros cultivos y para asimilar la idea de producir para el mercado. Un problema no menor, sería la escasa posibilidad de retener excedentes en las unidades campesinas, de no alterarse la actual concentración de acopiadores-comerciantes.

\section{Articulación regional y estrategia reproductiva:} venta de fuerza de trabajo

El proceso de semiproletarización se profundizó desde comienzos de los años 70, cuando la emigración estacional, además de la zafra azucarera, incluyó áreas tabacaleras y frutihortícolas de la región. La venta estacional de fuerza de trabajo continuaba siendo, durante los años 80 y los primeros años 90, una estrategia fundamental para la sobrevivencia del campesinado de Iruya. Paradójicamente, el factor esencial de la desestructuración se ha transformado en casi el único medio de obtener dinero para el pago de arriendos (en los casos en que este subsiste), y sobre todo para la compra de bienes no producidos por el campesino. 
En las semanas previas a la zafra azucarera, un intenso movimiento de familias campesinas se dirige al poblado de Iruya, desde distintos rodeos. Varios días después, abordan camiones que los trasladan a Iturbe (Jujuy), para continuar su viaje a los ingenios (sobre todo a San Martín del Tabacal), en trenes procedentes de La Quiaca. En la actualidad, se observa la cuasi-desaparición del contratista, al menos con las características de años atrás. Algunos comerciantes, que antes cumplían ese rol, realizan el transporte de los trabajadores temporarios entre Iruya e Iturbe. Los camiones de los comerciantes trasladan a los zafreros y familiares, junto a sus cargas, hasta galpones que poseen en Iturbe, a la espera (dos o tres días más) del ferrocarril contratado por el ingenio.

Cada jefe de familia (fichado titular en el ingenio), debe firmar una boleta que especifica el número de personas y de bultos trasladados hasta Iturbe. Luego deberá pagar con el primer mes de sueldo o al regreso, con la debida actualización, determinada por el bolichero. Cuando alguien se jubila, la ficha suele pasar a su hijo mayor o a otro miembro de la familia.

En años recientes, el avance de la tecnificación en las áreas receptoras se tradujo en una sensible disminución de la demanda estacional de mano de obra. Esto se debe a la incorporación de innovaciones tecnológicas (cosechadoras de caña, sembradoras de tabaco, cosechadoras de poroto) en algunos procesos productivos agrícolas de la economía regional. La mecanización ha sido más marcada en el sector azucarero, mereciendo señalarse que una cosechadora integral de caña desplaza entre 60 y 70 zafreros.

Una aproximación a la dimensión de los movimientos de la población campesina, asociados a la demanda estacional de trabajadores en la agricultura capitalista, se puede obtener mediante los censos realizados por el Ministerio de Salud y Acción Social de Salta, desde fines de los años 70 (Cuadro IV).

La retracción en la demanda de mano de obra no emana sólo de la incorporación de tecnología. En el marco de una profunda crisis socio-económica nacional, importantes empresas privadas del noroeste argentino acusan un sensible agravamiento de su situación financiera. Es el caso, por ejemplo, de los tres ingenios jujeños y los dos salteños. Cabe agregar que el más vinculado a la población de Iruya (San Martín del Tabacal), fue vendido a una empresa estadounidense en 1996. 
CUADRO IV

POBLACIÓN DE IRUYA EN ÉPOCA DE ZAFRA (Z) Y DURANTE EL PERÍODO AGRÍCOLA LOCAL (PA).

\begin{tabular}{|c|c|c|c|c|c|c|}
\hline & \multicolumn{2}{|c|}{1979} & \multicolumn{2}{|c|}{ 1985/86 } & \multicolumn{2}{|c|}{ 1989/90 } \\
\hline & $\mathbf{Z}$ & PA & $\mathbf{Z}$ & PA & $\mathbf{Z}$ & $\mathbf{P A}$ \\
\hline $\begin{array}{l}\text { Población } \\
\text { Diferencia }\left(\mathrm{N}^{\circ}\right) \\
\text { Diferencia (\%) }\end{array}$ & $\begin{array}{r}2.921 \\
2\end{array}$ & $9^{5.010}$ & $\begin{array}{r}3.085 \\
1\end{array}$ & $8^{4.113}$ & 3.618 & 4.422 \\
\hline
\end{tabular}

NotA: en 1979 se utilizan registros de fines de julio (Z) y de principios de mayo (PA); luego, tomamos julio/setiembre de 1985 y diciembre 1985/febrero 1986; por último, julio/setiembre 1989 y diciembre 1989/marzo 1990.

FUENTE: Ministerio de Salud y Acción Social de Salta.

\section{Articulación en el mercado de productos}

$\mathrm{El}$ «trueque recíproco equilibrado» subsiste a nivel local, o en ocasión de ferias en las que se congregan familias procedentes de distintos rodeos y también de distintos departamentos y provincias (Karasik, 1984). Entre las ferias más destacadas a nivel regional, cabe mencionar las de La Quiaca, Abra Pampa, Yavi, Rinconada, Cieneguillas, Santa Catalina (todas en Jujuy), y la de Iruya, en la cabecera del departamento salteño. En todas las ferias, actúan también los comerciantes locales, ejerciendo el intercambio desigual.

En la mayor parte del departamento, la distribución y circulación de productos es controlada por comerciantes afincados en la cabecera. En el poblado de Iruya hay cerca de una docena de almacenes, pero sólo tres concentran la mayor parte de las relaciones comerciales con los campesinos y, de esa manera, el poder a nivel local. Estos comercios pertenecen a familias establecidas también en Humahuaca e Iturbe, provincia de Jujuy, con residencias y actividades comerciales.

El intercambio desigual entre productos (con el dinero como patrón) continúa siendo bastante frecuente en los últimos años. Sin embargo, el trabajo de campo permitió comprobar que muchas compras realizadas por los campesinos son pagadas en dinero. Este proviene del trabajo estacional extrapredial, de jubilaciones obtenidas después de décadas como zafreros, de empleos oficiales en el ámbito local, combinado con prácticas prediales, y de la venta de productos al mercado. Los comer- 
ciantes de mayor poder son también quienes sacan la producción (habas, arvejas, papas) de los campesinos que habitan los rodeos más ligados a mercados extralocales (principalmente la quebrada de Humahuaca, San Salvador de Jujuy y la ciudad de Salta).

El precio obtenido en las ventas a esos comerciantes es notoriamente desfavorable para los campesinos. Por una bolsa de habas, de unos $35 \mathrm{Kg}$. (y no muchos venden más de dos o tres bolsas por temporada), obtienen el equivalente a un décimo del valor de la bolsa de azúcar de $50 \mathrm{Kg}$. Cuando los comerciantes entregan productos industrializados (yerba, fideos, aceite, arroz, vino, etc.), reciben dinero o productos que mediante la circulación revertirán en dinero (maíz, papas, habas, cueros, lanas, etc.).

Los principales almaceneros realizan buena parte de su acumulación a través de los mecanismos que los ligan a los campesinos semiproletarizados. Cada función de estos agentes (que pueden ser definidos como elementos «nexo»), supone un aporte a la descomposición del campesinado; sin embargo, la producción campesina requiere intercambio mercantil y, a menudo, venta de fuerza de trabajo, contribuyendo así, de algún modo, a la supervivencia del sector al que subordina.

En otro orden, hay que consignar que, pese a la adquisición de algunas tierras por ciertos comerciantes, no se han vinculado demasiado con la propiedad de grandes fundos en la zona de Iruya. En la actualidad, y aún cuando en determinados rodeos se continúe pagando arriendo y derechos de pastaje, la subordinación rentística es un factor de escasa trascendencia en el conjunto.

Cabe mencionar que el capital comercial en la zona es un producto exógeno y no una derivación de un proceso de diferenciación interna del campesinado. El poder de los comerciantes ha residido y reside en constituirse en canal de exportación estacional de fuerza de trabajo local. Pero también allí, de acuerdo al contexto regional, se hallan sus debilidades o limitaciones. El deterioro de la producción campesina y la merma en la salida estacional de fuerza de trabajo son procesos que podrían cuestionar la viabilidad de la acumulación de los comerciantes.

\section{CONSIDERACIONES FINALES}

El trabajo estacional, que comienza por el reclutamiento forzado, llega luego a constituirse en uno de los pilares de la reproducción de la po- 
blación campesina. Su evolución, desde entonces, no podrá entenderse sino a través de su vinculación con los mercados de trabajo de la agricultura capitalista.

Hace ya más de veinte años que se ha planteado una severa crisis de articulación en las relaciones hacienda-campesinado-ingenios. El cambio en las relaciones capital-trabajo ha provocado la merma en la demanda estacional de trabajadores y, por ende, serias dificultades al interior de las áreas emisoras. Sin embargo, no es sólo el avance de la mecanización en las producciones agrícolas regionales el factor interviniente. Lo fundamental pasa por la quiebra del modelo económico regional ante la caída de la demanda interna de sus producciones más importantes. Esto se desprende, a la vez, de las transformaciones operadas en la división nacional del trabajo. El cuestionamiento de la economía regional afecta inmediatamente las condiciones de reproducción de los campesinos de Iruya.

Ante el avance del estado de crisis y descomposición del campesinado del área, cabe interrogarnos por su futuro. Se han arriesgado hipótesis y formulado propuestas de acción. Estas últimas, se sintetizan en dos líneas principales, apoyadas ambas en la necesidad de incrementar la producción: una, esencialmente para el mercado; otra, con destino al autoconsumo.

Finalmente, y como hipótesis para nuevas investigaciones, agregamos: aún cuando pueda verificarse en un futuro inmediato, el incremento de la producción parcelaria en ciertos estratos, esto no será representativo de la población de Iruya en su conjunto. Esta seguirá, mayoritariamente, otros caminos: disolución de unidades productivas y comunidades; emigraciones definitivas; permanencia en la zona cada vez más anómica y con más marcada infrasubsistencia.

\section{BIBLIOGRAFÍA}

Bianchetti, M.: Por las tierras del marquesado de Tojo. Salta, 1978, inédito, 238 pp.

CAMPI, D.: «Estado Nacional y Desarrollo Regional. El Noroeste Argentino y el Modelo Agroexportador, 1870-1914». En: Meridiano, N. ${ }^{\circ}$ 2, Buenos Aires, marzo de 1996, pp. 39-49.

Fidalgo, A.: De quién es la Puna?. San Salvador de Jujuy, 1988, Ed. del Autor, 142 pp.

GolTE, J.: La racionaliad de la organización andina. Lima, 1980, I.E.P., 264 pp.

HEYNIG, K.: «Principales enfoques sobre la economía campesina». En: Revista de la CE$P A L$, N. $^{\circ} 16$, Santiago, 1982 , pp. 155-169.

$$
-658-
$$


ImPRENTA DEl PueBlo: Clamor de unos originarios de Santa Victoria e Iruya. Salta, 1882, Imprenta del Pueblo, 53 pp.

KARASIK, G.: «Intercambio tradicional en la puna jujeña». En: RUNA, Vol. 14, Buenos Aires, 1984 , pp. 51-91.

MADRAZO, G.: «Comercio interétnico y trueque recíproco equilibrado intraétnico». En: Desarrollo Económico, Vol. 21, N. ${ }^{\circ} 82$, Buenos Aires, julio-setiembre 1981, pp. 213-230.

Madrazo, G.: Hacienda y Encomienda en los Andes. La Puna argentina bajo el marquesado de Tojo. Siglos XVII a XIX. Buenos Aires, 1982, Fondo Editorial, 283 pp.

MORINA, J.: Iruya: Estudio de las Condiciones de Reproducción de la Economía Campesina. Buenos Aires, 1992, CONICET-Instituto de Geografía, F. F. y Letras, U.B.A., 242 pp.

OCLADE (Organización Claretiana para el Desarrollo): Proyecto de mejora de la producción animal del Departamento Iruya. Salta, 1988, OCLADE, 73 pp.

ReBoratti, C.: «Santa Victoria. Estudio de un caso de aislamiento geográfico». En: Desarrollo Económico, N. ${ }^{\circ}$ 55, Buenos Aires, octubre-diciembre 1974, pp. 481-506.

RePÚBliCa Argentina. Congreso Nacional. Cámara de Senadores, Diario de Sesiones, del 10 de agosto, 8 y 21 de setiembre de 1949.

REPÚblica ARgentina. INDEC. Censos Nacionales de Población, 1869 a 1991.

REPÚBLICA ARgEnTINA. INDEC. Censos Nacionales Agropecuarios de 1960, 1969 y 1988.

Rutledge, I.: Cambio Agrario e Integración. El desarrollo del capitalismo en Jujuy: 1550-1960. Tucumán, 1987, CICSO-F.F. y Letras, UBA, 297 pp.

SALTA. Dirección de Estadísticas y Censos. Censo Agropecuario de la Provincia de Salta, 1979. Salta, 1980.

SALTA. Ministerio de Salud y Acción Social. Atención Primaria de la Salud. Area Operativa Iruya. Rondas Médicas 1979-1990. Salta, 1991.

SCHEJTMAN, A.: «Economía campesina: lógica interna, articulación y persistencia». En: Revista de la CEPAL, N. ${ }^{\circ} 11$, Santiago, 1980, pp. 121-140.

WHITEFORD, S.: «Articulación social y poder: el zafrero y el contexto de la plantación azucarera». En: HERMITTE, E. y BARTOLOME, L. (comp.), Procesos de Articulación Social, Buenos Aires, 1977, Amorrortu, pp. 110-138.

RESUMEN: En este trabajo se analizan las condiciones de reproducción de la economía campesina en el Departamento Iruya, provincia de Salta. El estudio tiene un extenso marco temporal en los siglos XIX y Xx, y una permanente referencia al contexto regional y nacional. La subordinación rentística a los terratenientes, característica del siglo pasado, es parcialmente reemplazada por la subordinación al capital comercial local y al capital agroindustrial regional.Se explicitan las formas de articulación de la población campesina a la sociedad global, con énfasis en el mercado de productos y en el mercado de trabajo. Desde 1960, aproximadamente, se acentúa el deterioro cuali-cuantitativo de la producción parcelaria y se acelera la crisis y descomposición de este campesinado.

PALABRAS Clave: hacienda, campesinos, economía campesina, arriendo, trabajo temporario, trueque, valles altos, contratista, economía regional, capital comercial. 
KEY WORDS: landed property, peasants, peasant economy, renting, temporary workman, exchange, valley of highness, contractor, regional economy, commercial capital.

Mots ClEF: ferme, campagnard, économie campagnard, louage, travail temporaire, échange, vallé d'hauteur, contractant, économie régional, capital commercial. 